\title{
Biofilm Production and Antimicrobial Resistance among Uropathogens in Pediatric Cases: a Hospital Based Study
}

Dhiraj Shrestha, ${ }^{1,2}$ Pratigya Thapa, ${ }^{1}$ Dinesh Bhandari, ${ }^{1,3}$ Hiramani Parajuli, ${ }^{1}$ Prakash Chaudhary, ${ }^{1}$ Kabi Thapa, ${ }^{1}$ Vijay Kumar Sharma, ${ }^{4}$ Pradeep Kumar Shah ${ }^{1}$

${ }^{1}$ Department of Microbiology, Tri-Chandra Multiple Campus, Ghantaghar, Kathmandu, Nepal, ${ }^{2}$ Department of Microbiology, Shi-Gan International College of Science and Technology (SICOST), Chakrapath, Kathmandu, Nepal, ${ }^{3}$ School of Public Health, University of Adelaide, Australia, ${ }^{4}$ Department of Biochemistry, Institute of Medicine, Tribhuvan University Teaching Hospital, Maharajgunj, Kathmandu, Nepal.



\section{INTRODUCTION}

Urinary tract infection (UTI), an infection of urethra, bladder, ureters and/or kidney, has significant morbidity and mortality. ${ }^{1,2}$ Outpatient morbidity of UTI in Nepal was $311,944 .^{3}$ UTIs affect at least $3.6 \%$ of boys and $11 \%$ of girls. ${ }^{4} \mathrm{UTI}$ can lead to terminal renal disease in children. ${ }^{5}$ Epidemiological reports point Escherichia coli as the most common cause of UTI in children. ${ }^{6,7}$

Biofilm, which account $80 \%$ of infections, is a sessile cells embedded in extracellular matrix. ${ }^{8,9}$ The matrix assist in exhibiting an altered phenotype e.g. increased antimicrobial resistance (AMR).$^{10}$ Biofilm thus boosts pathogenicity of uropathogenic $E$. coli (UPEC). ${ }^{11}$

$A M R$, i.e. resistance against previously effective antibiotics, is the global threats to human health. ${ }^{12,13}$ AMR increases morbidity, mortality, health-care cost and hospitalization. ${ }^{14}$ Antibiotic choice should be based on AMR profiles of local strains varying temporally and geographically. ${ }^{15} \mathrm{UTI}$ in children is treated empirically to avoid complications. ${ }^{16}$ Biofilm associated AMR has burthen the management of UTI. The study was done to insight uropathogens in pediatric UTI patients along with their AMR pattern and biofilm producing profile.

\section{METHODS}

The prospective study was conducted in the department of Microbiology of Alka Hospital, Lalitpur, Nepal; a tertiary level hospital. A total of 353 clean catch urine samples from children under 13 years of age were processed during the study period (July 2014 to January
DOI: http://dx.doi.org/10.3126/

inhrc.v16i2.20307
Correspondence: Mr Dhiraj Shrestha. Department of Microbiology, Shi-Gan International College of Science and Technology, Chakrapath, Kathmandu, Nepal. Email: hiraj.diamond@gmail.com, Phone: +97779841716105. 
2015).

Urine culture was performed on routine culture media by semi-quantitative method as described in World Health Organization (WHO) manual. ${ }^{17}$ Briefly, $1 \mu \mathrm{L}$ of urine was inoculated on MacConkey and blood agar plate by streaking using calibrated loop $(2 \mathrm{~mm})$, and incubated aerobically for $18-48 \mathrm{hrs}$ at $37{ }^{\circ} \mathrm{C}$. Growth of 100 colonies or more, i.e. $10^{5}$ colony forming units (CFU) $/ \mathrm{mL}$ urine, was considered as positive growth. Isolation and identification of microorganisms were done by standard microbiological operation procedure as described in the Manual of Clinical Microbiology. ${ }^{18}$

Antimicrobial susceptibility testing of all isolates against in-use antibiotics was performed by Kirby-Bauer disc diffusion method and interpretation of the results was done as described by Clinical and Laboratory Standard Institute (CLSI) 2013.19 Antibiotic discs used were amikacin $(30 \mu \mathrm{g})$, ampicillin $(10 \mu \mathrm{g})$, cefepime $(30 \mu \mathrm{g})$, cefoxitin $(30 \mu \mathrm{g})$, cephalexin $(30 \mu \mathrm{g})$, ciprofloxacin $(5 \mu \mathrm{g})$, cotrimoxazole $(1.25 / 23.75 \mu \mathrm{g})$, gentamicin $(10 \mu \mathrm{g})$, imipenem $(10 \mu \mathrm{g})$, nitrofurantoin $(300 \mu \mathrm{g})$, norfloxacin $(10 \mu \mathrm{g})$, ofloxacin $(5 \mu \mathrm{g})$, piperacillin $(100 \mu \mathrm{g})$, and vancomycin $(30 \mu \mathrm{g})$. Organisms resistant to three or more classes of antibiotics were considered to be multidrug resistance (MDR). Similarly, extensively drug- resistance (XDR) and pandrug- resistance (PDR) organisms were considered as per international consensus. ${ }^{20}$

Detection of biofilm producers among isolates was done by culturing on Congo red agar. Intensity of color change of Congo red agar on microbial growth is proportional to the biofilm production by the organisms. Considering the intensity of color change, organisms were categorizedas strong biofilm producers, moderate biofilm producers, weak biofilm producers and biofilm non producers.

Ethical approval was obtained from Ethical Review Board, Nepal Health Research Council (NHRC), Nepal (Reg. no. 147/2014). Written informed consent was obtained from the guardian of children before enrolling to the study.

\section{RESULTS}

A total of 353 clean catch urine samples from children, under 13 years of age, were included under the study. The median age of children was 4 years (Interquartile range $=5$ years) with boys to girls ratio of $1: 1.37$. Samples from $64(18.13 \%)$ children showed positive growth in culture with boys to girls ratio of $1: 1.21$. UTI was more frequent in Indo-Aryan race compared to that in SinoTibetan race with ratio of 1.9:1 (Table 1).

\section{Table 1. Distribution of patients.}

Total children UTI confirmed

\begin{tabular}{lrr}
\hline Types of patients & & \\
Out patients & 282 & 55 \\
In patients & 71 & 9 \\
Gender distribution & & \\
Boys & 150 & 29 \\
Girls & 203 & 35
\end{tabular}

Age distribution (Median age $=4$ years, Interquartile range $=5$ years)

\begin{tabular}{lrr}
$<3$ months & 33 & 13 \\
3 months-3 years & 129 & 27 \\
$>3$ years & 191 & 24 \\
Race distribution & & \\
Sino-Tibetan & 155 & 22 \\
Indo-Aryan & 198 & 42 \\
\hline Total children & 353 & 64 \\
\hline
\end{tabular}

Ten different bacterial genera were isolated. E. coli, $44(68.8 \%)$ was the predominant isolate followed by Klebsiella spp., 6 (14.1\%) (Table 2).

\begin{tabular}{|c|c|c|}
\hline $\begin{array}{l}\text { Gram's type of } \\
\text { bacteria }\end{array}$ & Bacteria isolated & $\begin{array}{r}\text { Frequency } \\
(\%)\end{array}$ \\
\hline \multirow{9}{*}{$\begin{array}{l}\text { Gram-negative } \\
\text { bacteria }\end{array}$} & $\begin{array}{r}\text { Acinetobacter } \\
\text { spp. }\end{array}$ & $1(1.6)$ \\
\hline & C. freundii & $1(1.6)$ \\
\hline & Enterobacter spp. & $1(1.6)$ \\
\hline & E. coli & $44(68.8)$ \\
\hline & Klebsiella spp. & $6(9.4)$ \\
\hline & M. morganii & $2(3.1)$ \\
\hline & Proteus spp. & $3(4.7)$ \\
\hline & Providencia spp. & $3(4.7)$ \\
\hline & P. aeruginosa & $1(1.6)$ \\
\hline \multirow[t]{2}{*}{$\begin{array}{l}\text { Gram-positive } \\
\text { bacteria }\end{array}$} & S. aureus & $2(3.1)$ \\
\hline & Total & $64(100)$ \\
\hline
\end{tabular}

In $E$. coli isolates, resistivity was highest to ampicillin (95.5\%) and least to amikacin (6.8\%). In other Gramnegative isolates, resistivity was highest to cefepime (33.3\%) and least to amikacin (11.1\%), gentamicin (11.1\%), and piperacillin (11.1\%) (Table 3). 
Table 3. Antibiotic resistivity profile of isolates.

\begin{tabular}{|c|c|c|c|c|c|c|c|c|}
\hline \multicolumn{2}{|l|}{ Class of antibiotics } & & E. coli $(\mathrm{n}=44)^{*}$ & \multicolumn{3}{|c|}{$\begin{array}{r}\text { Other Gram-negative } \\
\text { isolates }(n=18)^{*}\end{array}$} & \multicolumn{2}{|c|}{ S. aureus $(\mathrm{n}=2)$} \\
\hline \multirow{2}{*}{\multicolumn{2}{|c|}{ Aminoglycosides }} & & $6.8 \%$ & & & $11.1 \%$ & & NT \\
\hline & Gentami & & $36.4 \%$ & & & $11.1 \%$ & & $0 \%$ \\
\hline \multicolumn{2}{|l|}{ Beta lactam } & & NT & & & $11.1 \%$ & & NT \\
\hline Carbapenems & Imipener & & NT & & & $0 \%$ & & NT \\
\hline Cephalosporins I & Cephalex & & $44.2 \%$ & & & NT & & NT \\
\hline \multicolumn{2}{|l|}{ Cephalosporins II } & & NT & & & NT & & $100 \%$ \\
\hline \multicolumn{2}{|l|}{ Cephalosporins IV } & & NT & & & $33.3 \%$ & & NT \\
\hline \multirow{3}{*}{\multicolumn{2}{|c|}{ Fluoroquinolones }} & $\operatorname{acin}$ & $40.9 \%$ & & & $27.8 \%$ & & $0 \%$ \\
\hline & & & $38.6 \%$ & & & $22.2 \%$ & & NT \\
\hline & & & NT & & & NT & & $0 \%$ \\
\hline \multicolumn{2}{|l|}{ Glycopeptides } & & NT & & & NT & & $0 \%$ \\
\hline Nitrofurans & Nitrofura & htoin & $13.6 \%$ & & & NT & & $0 \%$ \\
\hline Penicillins & Ampicilli & & $95.5 \%$ & & & NT & & $100 \%$ \\
\hline \multicolumn{2}{|l|}{ Sulphonamide } & razole & $61.4 \%$ & & & $27.8 \%$ & & $0 \%$ \\
\hline \multicolumn{9}{|c|}{$\mathrm{NT}=$ Not tested, *Percentage calculated on $\mathrm{n}$} \\
\hline \multirow{2}{*}{ Bacteria isolated } & Biofilm production & & & & & \multirow{2}{*}{\multicolumn{2}{|c|}{ MDR isolates }} & \multirow{2}{*}{$\begin{array}{l}\text { Total } \\
\text { isolates }\end{array}$} \\
\hline & Strong producer & Moderate producer & Weak produce & & Non producer & & & \\
\hline Acinetobacter spp. & 0 & 0 & & 1 & 0 & & 0 & 1 \\
\hline C. freundii & 0 & 0 & & 0 & 1 & & 0 & 1 \\
\hline Enterobacter spp. & 0 & 1 & & 0 & 0 & & 0 & 1 \\
\hline E. coli & 9 & 9 & & 5 & 21 & & 23 & 44 \\
\hline Klebsiella spp. & 2 & 1 & & 1 & 2 & & 0 & 6 \\
\hline M. morganii & 0 & 0 & & 1 & 1 & & 0 & 2 \\
\hline Proteus spp. & 0 & 0 & & 2 & 1 & & 0 & 3 \\
\hline Providencia spp. & 0 & 1 & & 0 & 2 & & 0 & 3 \\
\hline P. aeruginosa & 0 & 1 & & 0 & 0 & & 0 & 1 \\
\hline S. aureus & 0 & 0 & & 2 & 0 & & 0 & 2 \\
\hline Total & 11 & 13 & 1 & 2 & 28 & & 23 & 64 \\
\hline \multirow{3}{*}{\multicolumn{3}{|c|}{$\begin{array}{l}\text { Of } 64 \text { isolates, } 23(35.93 \%) \text { were MDR. All } 23 \text { MDR strains } \\
\text { were E. coli isolates. Biofilm production in all isolates } \\
\text { was higher i.e. } 36(56.25 \%) \text { (Table } 4) \text {. }\end{array}$}} & XDR & 9 & 5 & 3 & 0 & 1 \\
\hline & & & Possible XDR & 11 & 2 & 3 & 1 & 5 \\
\hline & & & PDR & 0 & 0 & 0 & 0 & 0 \\
\hline \multicolumn{3}{|c|}{ Higher rate of antimicrobial resistance was found in } & Possible PDR & 1 & 1 & 0 & 0 & 0 \\
\hline
\end{tabular}

biofilm producing $E$. coli strains. (Table 5 )

\section{Table 5. MDR profile of $E$. coli as per biofilm}

producing ability.

\begin{tabular}{llllll}
$\begin{array}{l}\text { Antimicro- } \\
\text { bial resis- } \\
\text { tance }\end{array}$ & $\begin{array}{l}\text { Total } \\
\text { iso- } \\
\text { lates }\end{array}$ & $\begin{array}{l}\text { Strong } \\
\text { pro- } \\
\text { ducer }\end{array}$ & $\begin{array}{l}\text { Moder- } \\
\text { ate } \\
\text { pro- } \\
\text { ducer }\end{array}$ & $\begin{array}{l}\text { Weak } \\
\text { pro- } \\
\text { ducer }\end{array}$ & $\begin{array}{l}\text { Non } \\
\text { pro- } \\
\text { ducer }\end{array}$ \\
\hline Non MDR & 21 & 1 & 3 & 2 & 15 \\
MDR & 23 & 8 & 6 & 3 & 6
\end{tabular}

\section{DISCUSSION}

Increasing AMR among common isolates is posing difficulty in the management of UTI in pediatrics. Our study revealed high AMR and biofilm production among uropathogens. In our study, bacterial growths of $\geq 10^{5}$ $\mathrm{CFU} / \mathrm{mL}$ in culture were considered as positive growth and thus UTI. ${ }^{17}$ Only 64 (18.13\%) samples showed positive growth. This signifies the need for review of in-use general microbiological methods and clinical examination. 
Prior antibiotic treatment before submitting the urine sample, and other UTI like clinical conditions could be the factors responsible for low growth positivity.

In our study, the ratio of outpatients to inpatients was 3.97:1, while that in UTI confirmed children was 6.11:1. This implies higher prevalence of UTI in community children. In our study, boys to girls ratio was 1:1.21 in UTI confirmed children. UTI is more prevalent in girls, the natural epidemiology pattern. ${ }^{21}$ Girls are more frequently affected by UTI due to colonizing colonic Gram-negative bacteria in urethra because of its anal proximity and shorter length. ${ }^{22}$ Higher UTI prevalence in girls was also reported by other studies. ${ }^{2,6}$ UTI was more frequent in Indo-Aryan race children compared to SinoTibetan race children with ratio of 1.9:1.

Gram-negative bacteria were predominant isolates 62 (96.88\%) compared to 2 (3.12\%) Gram-positive bacteria. Enterobacteriaceae family comprised of 54 (84.38\%) bacteria. E. coli was the most predominant isolate 44 (68.75\%), followed by Klebsiella spp. 6 (9.38\%). This concords with reports from other studies. ${ }^{6,7,15,21,23}$ UTI onsets when $E$. coli or other enterobacteria accesses and ascends the urethra. These organisms are among gastrointestinal tract flora colonizing periurethral area. ${ }^{24}$

The evolution of resistance against antibiotics is not a new phenomenon. And there is continual increase in reporting of $A M R$ in recent years. In this study, E. coli, principal pathogen isolated, showed high resistivity to ampicillin (95.5\%) and least to amikacin (6.8\%). This concord with other studies. ${ }^{6,7,15,21,23}$ Likewise, imipenem and amikacin were found most effective against other Gram-negative isolates and cefepime the least. Moreover, ciprofloxacin, co-trimoxazole, gentamicin and nitrofurantoin were found most effective for Grampositive isolates. Development of MDR strains among common isolates of health care associated infection has been a major concern due to development of MDR strains among common isolates. Only 23 (35.93\%) isolates were found MDR. This was similar to the other study. ${ }^{2}$

Co-trimoxazole, commonly used to treat pediatric UTI orally, was effective only against one third of isolates. Nitrofurans can still be relied upon as $1^{\text {st }}$ line choice, the economical option too. But, higher resistance against fluoroquinolones renders it ineffective for $2^{\text {nd }}$ line treatment. One of the most important findings in this study is the resistance to cephalexin with resistance rate of $44.2 \%$ for $E$. coli which portrays lower generation cephalosporins as unreliable empiric antibiotics. Empiric use of amikacin until the sensitivity pattern is available might be a reasonable choice. For avoiding complications, most children are treated empirically with antibiotics even before culture and susceptibility reports arrives. ${ }^{21}$ Resistance against antibiotics is increasing nowadays in community patients. Also, lack of access to health facilities and inadequate public awareness are added worries. ${ }^{25}$ In recent years, AMR is rising, self-medication being one but not the only reason. ${ }^{26}$ Furthermore, antibiotic resistance is the holistic effect of inappropriate antibiotic policies, poor surveillance plus compliance, easy access to antibiotics, self-medication of antibiotics with poor adherence, suboptimal dosing, diagnostic errors, counterfeit drug of low quality, uncontrolled antibiotics use in agriculture and indiscriminate use of antibiotics without proper diagnosis or identification of causative agent..$^{25,27,28}$

Biofilm production was higher in the isolates i.e. 36 (56.25\%). In this study, biofilm production was found associated with high MDR, XDR and possible PDR. The biofilm stage determines the level of resistance. In initial phase, antibiotics and host immune system are the most effective. ${ }^{10}$ Once the bacteria begin to secrete EPS and the attachment becomes irreversible, biofilm resist more against antibiotics and host immunity. ${ }^{10}$ In addition, the spread of resistance markers and virulence factors can be promoted. ${ }^{29}$ Combination therapy with macrolides (erythromycin, clarithromycin, and azithromycin) is recommended for biofilm-associated infections by different studies. Macrolides inhibits alginate thus averts matrix formation fort biofilm. ${ }^{30}$

Asia is regarded as one of the epicenters of AMR. ${ }^{31}$ Inappropriate antibiotics treatment is the common healthcare practice, making this region the high risk area for AMR evolution. Our study highlights a high rate of MDR among uropathogens and a broad range of uropathogens in this setting. Variability of antibiotic resistance pattern as per different regions and recent continuous increase in resistant strains to new antibiotics has posed great difficulty in selecting appropriate antimicrobial agents for management of infection they caused. Also leading to increase in cost with need of new costly drugs as wells as prolonged hospital stay. Since, the study was limited to single tertiary setting, broader surveillance is must to disseminate local resistance profile of prevalent uropathogens. This will ensure the optimal empirical therapy of UTI. And macrolides should be supplement along with other antibiotic therapy to circumvent evolution of resistance by biofilm production. The small sample size from single tertiary setting outlines the limitation of the findings to generalize in the larger population. Also phenotypic characterization cannot be solely relied upon to describe the inherent cause of the AMR in population. 


\section{CONCLUSIONS}

Majority of uropathogens causing UTI in pediatrics were Gram-negative bacteria with predominance of $E$. coli in a tertiary care setup. Amikacin and gentamicin were found effective against most of the Gramnegative bacterial isolates, including $E$. coli. Onethird of the isolates were found to be MDR. The study demonstrates high resistance to commonly prescribed antibiotics. Thus, testing of antimicrobial susceptibility of uropathogens is preeminent before starting antibiotic therapy. Majority of the isolates were biofilm producers rendering higher antimicrobial resistance. Macrolides can be supplemented along with antibiotics.

\section{ACKNOWLEDGEMENTS}

We acknowledge all the children and their guardians for their generous support.

\section{REFERENCES}

1. Centers for Disease Control and Prevention (CDC). Catheter associated Urinary Tract Infections (CAUTI). Centers for Disease Control and Prevention, 1600 Clifton Road Atlanta, GA 30329-4027, USA.[Web Page].

2. Sharma AR, Bhatta DR, Shrestha J, Banjara MR. Antimicrobial Susceptibility Pattern of Escherichia coli Isolated from Uninary Tract Infected Patients Attending Bir Hospital. Nepal J Sci Technol. 2013;14(1):177-184. [Full Text].

3. Department of Health Services Government of Nepal Ministry of Health. Annual Report 2014/2015.; 2015. [Full Text].

4. National Collaborating Centre for Women's and Children's Health (UK). Urinary tract infection in children diagnosis, treatment and longterm management Clinical Guideline Urinary tract infection in children diagnosis, treatment and longterm management. 2007. [Full Text].

5. Kennedy KM, Glynn LG, Dineen B. A survey of the management of urinary tract infection in children in primary care and comparison with the NICE guidelines. BMC Fam Pract. 2010;11(1):1-6. [Full Text].

6. Singh SD, Madhup SK. Clinical profile and antibiotics sensitivity in childhood urinary tract infection at Dhulikhel Hospital. Kathmandu Univ Med J. 2013;11(4(44)):319324. [Full Text].

7. Mirsoleymani SR, Salimi M, ShareghiBrojeni M, Ranjbar M, Mehtarpoor M. Bacterial Pathogens and Antimicrobial Resistance Patterns in Pediatric Urinary Tract Infections: A Four-Year Surveillance Study (2009-2012). Int J Pediatr.
2014;(126142). [Full Text].

8. Römling $\mathrm{U}$, Balsalobre C. Biofilm infections, their resilience to therapy and innovative treatment strategies. $J$ Intern Med. 2012;272(6):541-561. [Full Text].

9. Allison DG. The Biofilm Matrix. Biofouling. 2003;19(2):139-150. [ull Text].

10. Donlan R. Biofilms: Microbial life on surfaces. Emerg Infect Dis. 2002;8(9):881-890. [Full Text].

11. Soto SM. Importance of Biofilms in Urinary Tract Infections: New Therapeutic Approaches. Adv Biol. 2014;(543974):1-13. [ㄹll Text].

12. Liu YY, Wang Y, Walsh TR, Yi LX, Zhang R, Spencer J et al. Emergence of plasmid-mediated colistin resistance mechanism MCR-1 in animals and human beings in China: a microbiological and molecular biological study. Lancet Infect Dis. 2016;16(2):161-168. [Full Text].

13. General Assembly of the United Nations. PRESS RELEASE: High-Level Meeting on Antimicrobial Resistance. OPGA/ WHO/FAO/OIE Joint News Release. [Web Page]. Published 2016. Accessed September 30, 2016.

14. Shaikh N, Morone NE, Bost JE, Farrell MH. Prevalence of Urinary Tract Infection in Childhood: A Meta-Analysis. Pediatr Infect Dis J. 2008;27(4):302-308. [Full Text].

15. Moore CE, Sona S, Poda S, et al. Antimicrobial susceptibility of uropathogens isolated from Cambodian children. Paediatr Int Child Health. 2016;36(2):113-117. [Full Text].

16. Miranda ÉJP De, Oliveira GSS De, Roque FL, Santos SR Dos, Olmos RD, Lotufo PA. Susceptibility to antibiotics in urinary tract infections in a secondary care setting from 2005-2006 and 2010-2011, in São Paulo, Brazil: data from 11,943 urine cultures. Rev Inst Med trop S Paulo. 2014;56:313-324. [Full Text]

17. Vandepitte J, Engbaek K, Rohner P, Piot P, Heuck CC, World Health Organization. Basic Laboratory Procedures in Clinical Bacteriology.2nd ed. World Health Organization, Geneva; 2003.[Full Text].

18. Versalovic J, Carroll KC, Funke G, Jorgensen JH, Landry ML, Warnock DW, eds. Manual of Clinical Microbiology. 10th ed. American Society of Microbiology; 2011.

19. Clinical and Laboratory Standards Institute (CLSI). Performance Standards for Antimicrobial Susceptibility Testing. 23rd ed. Clinical and Laboratory Standards Institute: Wayne, PA.; 2013.

20. Magiorakos AP, Srinivasan A, Carey RB, et al. Multidrugresistant, extensively drug-resistant and pandrug-resistant bacteria: an international expert proposal for interim 
standard definitions for acquired resistance. Clin Microbiol Infect. 2012;18(3):268-281. [ [Full Text].

21. Ghorashi Z, Ghorashi S, SoltaniAhari H, Nezami N. Demographic features and antibiotic resistance among children hospitalized for urinary tract infection in northwest Iran. Infect Drug Resist. 2011;4:171-176. [티l Text].

22. Forbes B, Sham D, Weissfeld A. Bailey and Scott's Diagnostic Microbiology. 12th ed. Mosby Elsevier; 2007.

23. van der Meeren BT, Chhaganlal KD, Pfeiffer A, et al. Extremely high prevalence of multi-resistance among uropathogens from hospitalised children in Beira, Mozambique. South African Med J. 2013;103(6):382-386. [Full Text].

24. McLellan LK, Hunstad DA. Urinary Tract Infection: Pathogenesis and Outlook. Trends Mol Med. 2016;22(11):946-957. [Full Text].

25. Siegel JD, Rhinehart E, Jackson M, Chiarello L, the Healthcare Infection Control Practices Advisory Committee (HICPAC). Management of MultidrugResistant Organisms in Healthcare Settings, 2006.Am J Infect Control. 2007;35(10 Suppl 2):S165-93. [Full Text].

26. Costin S, Oana M, Feier M, Olteanu A. Antibiotic resistance pattern of the strains isolated in urinary tract infections in the last semester in the military hospital. BMC Infect Dis. 2013;13(Suppl 1):P33-P33. [Full Text].
27. American Society for Microbiology. A Report from the American Academy of Microbiology, Antibiotic Resistance: An Ecological Perspective of an Old Problem. ASM Press, Washington DC; 2009.[Full Text].

28. Dalhoff A. Global fluoroquinolonesresistance epidemiology and implications for clinical use. InterdiscipPerspect Infect Dis. 2012;2012(976273):1-37. [Full Text].

29. Vuong C, Kocianova S, Voyich JM, et al. A Crucial Role for Exopolysaccharide Modification in Bacterial Biofilm Formation, Immune Evasion, and Virulence. J Biol Chem. 2004;279(52):54881-54886. [Full Text].

30. Ichimiya T, Takeoka K, Hiramatsu K, Hirai K, Yamasaki T, Nasu M. The influence of azithromycin on the biofilm formation of Pseudomonas aeruginosa in vitro. Chemotherapy. 1996;42(3):186-191. [Full Text].

31. Kang C-I, Song J-H. Antimicrobial Resistance in Asia: Current Epidemiology and Clinical Implications. Infect Chemother. 2013;45(1):22-31. [Full Text]. 